\title{
Association between Polymorphisms of Glutathione S-Transferase and Progression to Cervical Cancer in Women from Burkina Faso and Mali
}

\author{
Teega-Wendé Clarisse Ouedraogo', Florencia Wendkuuni Djigma ${ }^{1,2 *}$, \\ Théodora Mahoukèdè Zohoncon ${ }^{1,3}$, Boureima Idani' ${ }^{1}$, Abdoul Karim Ouattara1, \\ Pegdwendé Abel Sorgho1,2, Dorcas Obiri-Yeboah4, Prosper Bado1, Mah Alima Esther Traore1, \\ Birama Diarra5 $^{5}$ Albert Théophane Yonli ${ }^{1,2}$, Charlemagne Ouedraogo ${ }^{6}$, Jacques Simpore ${ }^{1,2,3}$ \\ ${ }^{1}$ Laboratory of Molecular Biology and Genetics (LABIOGENE), University Joseph Ki-Zerbo, Ouagadougou, Burkina Faso \\ ${ }^{2}$ Pietro Annigoni Biomolecular Research Centre (CERBA), Ouagadougou, Burkina Faso \\ ${ }^{3}$ University Saint Thomas d'Aquin, Faculty of Medicine, Ouagadougou, Burkina Faso \\ ${ }^{4}$ Department of Microbiology and Immunology, School of Medical Sciences, University of Cape Coast, PMB, Cape Coast, Ghana \\ ${ }^{5}$ University of Techniques and Technologies Sciences, Faculty of Medicine and Odontostomatology, Bamako, Mali \\ ${ }^{6}$ University Joseph Ki-Zerbo, UFR/SDS, Ouagadougou, Burkina Faso \\ Email: ^florencia.djigma@gmail.com, ${ }^{\star}$ f.djigma@labiogene.org
}

How to cite this paper: Ouedraogo, T.-W.C., Djigma, F.W., Zohoncon, T.M., Idani, B., Ouattara, A.K., Sorgho, P.A., Obiri-Yeboah, D., Bado, P., Traore, M.A.E., Diarra, B., Yonli, A.T., Ouedraogo, C. and Simpore, J. (2020) Association between Polymorphisms of Glutathione S-Transferase and Progression to Cervical Cancer in Women from Burkina Faso and Mali. Journal of Biosciences and Medicines, 8, 12-25. https://doi.org/10.4236/jbm.2020.84002

Received: February 25, 2020

Accepted: March 28, 2020

Published: March 31, 2020

Copyright () 2020 by author(s) and Scientific Research Publishing Inc. This work is licensed under the Creative Commons Attribution International License (CC BY 4.0).

http://creativecommons.org/licenses/by/4.0/

\begin{abstract}
Although persistence of high-risk human papillomavirus infection is the main risk factor, Glutathione S-Transferase highly polymorphic enzyme involved in the metabolism of xenobiotics, is a good candidate gene. The objective of this study was to compare the polymorphisms of Glutathione S-Transferase M1-null in women with cancerous lesions and without lesions. This study consisted of 322 uterine cervix samples of women from Mali and Burkina Faso with Cervical Intra-epithelial Neoplasia 2 and 3, adenocarcinoma and squamous cell carcinoma and 100 women with no lesions. Human Papillomavirus genotyping was performed by Real-time multiplex Polymerase Chain Reaction. Glutathione S-Transferase gene polymorphisms were determined using conventional Polymerase Chain Reaction followed by migration on agarose gel. A statistically significant association with high relative risks of 10.77 for the development of High grade Superficial or Squamous Intra-epithelial Lesion (95\% CI $=5.59-20.72 ; \mathrm{p}<0.001)$, and 13.20 for cancer development $(95 \% \mathrm{CI}=6.79-25.63 ; \mathrm{p}<0.001)$ was found in women with the null genotype of Glutathione S-Transferase M1 in the study population. In Burkina Faso and Mali, Glutathione S-Transferase M1-null presented relative risks of 9 and 11.05 for high-grade lesions, 15 and 11.40 for cancer. Similarly,
\end{abstract}


significant results had been observed in women with human papillomavirus positive and human papillomavirus negative. The results of the present study support the idea that the deletion of Glutathione S-Transferase M1 plays a crucial role in the progression of high-grade lesions and cervical cancer.

\section{Keywords}

Glutathione S-Transferase M1-Null, Cervical Cancer, Burkina Faso, Mali

\section{Introduction}

Human papillomavirus (HPV) infection, a sexually transmitted disease, is the leading risk factor for cervical cancer [1] [2]. In 2018, the global incidence of cervical cancer was 569,847 cases and 311,365 deaths [3]. It is the fourth most common cancer and the second in terms of mortality in women worldwide [3]. According to some previous studies, $85 \%$ of cervical cancer cases are recorded in low and middle income countries [4] [5], with $87 \%$ of world deaths due to the disease as estimated by WHO. In West Africa, 31,955 cases and 23,529 deaths per year have been reported [6]. In Burkina Faso and Mali, where the disease is the first most common diagnosed cancer, the incidence was estimated at 2517 and 2206 cases respectively with 2081 and 1704 deaths per year [6] [7]. A frequency of $72.31 \%$ and $48.8 \%$ of HR-HPV were found in cancerous and precancerous lesions tissues of the uterine cervix in women in Burkina Faso [8] [9]. Although high-risk human papillomaviruses are identified as the major causative agent of cervical cancer, viral clearance has been observed in some women. This suggests that other cofactors (environmental or genetic) play an important role in viral persistence leading to progression to carcinogenesis [10]. Metabolized xenobiotic enzymes have been shown to be important risk modifiers in human carcinogenesis [11]. Phase I enzymes (cytochrome P450) activate procarcinogens, while reactive intermediates are inactivated by phase II enzymes [12] [13]. A possible mutation of the latter enzyme could have consequences on the carcinogenic compounds' elimination. Therefore, phase II metabolite enzymes polymorphisms have been designated according to the literature as cofactors in the HPV infections progression to precancerous and cancerous lesions.

Glutathione S-transferase (GST, E.C 2.5.1.18) is a super family of enzymes metabolizing xenobiotic substances with a high degree of specificity of conjugation of glutathione (GSH). These enzymes are essential for the metabolism of harmful electrophilic compounds and are responsible for the response to oxidative stress. There are 8 classes of enzymes: alpha (GSTA), mu (GSTM), theta (GSTT), pi (GSTP), sigma (GSTS), kappa (GSTK), omega (GSTO) and zeta (GSTZ), which are involved in detoxification of drug compounds, carcinogens, and for the inhibition of oxidative damage in tissues [14]. The GSTM1 and GSTT1 subclasses belonging respectively to the $m u$ and theta classes, are highly polymorphic genes [15] [16] and the most encountered in the literature. There 
are two types of glutathione S-transferase $\mathrm{M} 1$ and $\mathrm{T} 1$ genes polymorphisms: nucleotide variation (G2619C for GSTM1 and A310C for GSTT1) and complete gene deletion or homozygous deletion (null genotype), associated with loss of enzyme activity. The nucleotide variations lead to two non-suppressive genotypes (called active or present genotypes) with an active presence of the enzyme. GSTM1 and GSTT1 are located on chromosomes 1p13.3 and 22q11.23 respectively and the enzymes participate in conjugation and detoxification. Any variation in the activity of these enzymes could potentially have significant repercussions on the fate of drug, carcinogenic compounds and on the quantities of metabolites produced. Individuals with zero genotype have somewhat reduced overall detoxification capacity [16]. They are associated with the susceptibility to develop certain diseases, such as infectious diseases, cancers and others, probably because of increased susceptibility to the harmful effects of oxidative stress, environmental toxins and carcinogens [17]-[22].

In recent years, much data have been generated about the prevalence and the distribution of HPV genotypes especially in general population in West Africa and some suggest the emergence of non-HPV16/18 genotypes in precancerous lesions and cancers [23]. However, there are few association studies about HPV infections, genetics factors and progression to cervical cancer. The present case-control study aimed to compare the polymorphisms of GSTM1-null in women with cancerous lesions and without lesions in Burkina Faso and Mali.

\section{Material and Methods}

\subsection{Study Framework and Sampling}

The study concerned samples collected in Burkina Faso and Mali. A total of 234 archived cervical tissue samples embedded in paraffin blocks and 100 freshly taken samples from the endocervix were used in this study. Among cancer 234 tissue samples, 153 came from the Anatomy and Cytology Pathology service of Bamako in Mali (57 were cancerous and $96 \mathrm{HSIL}$ ) and 81 came from Anatomy and Cytology Pathological Laboratory of Yalogdo OUEDRAOGO University Hospital of Ouagadougou, Burkina Faso (67 were cancerous and 14 HSIL). All samples had already been subjected to histological analysis to determine the type of lesion. We included in our study the samples from Burkina Faso taken from January to July 2018 and the samples from Mali taken between 2016 and 2017.

Our study was a cross-sectional case-control study with a retrospective collection of samples and socio-demographic data of women in Mali and a prospective collection of samples and data in Burkina Faso. Data was collected from archived patient files from different laboratories. Samples with lesions were considered cases.

In terms of controls, we selected the women who consented to the study and to being screened for cervical lesions by visual inspection with acetic acid and Lugol's iodine (VIA/VILI). A woman was included in the control group if her 
VIA/VILI was negative. It should be noted, however, that a fresh sample of the endocervix was taken from each woman before the VIA/VILI. All non-pregnant women and young girls in sexual activity were approached to participate in the study. Any virgin, menstruating or pregnant woman or women who had a total hysterectomy was not included in the study.

\subsection{DNA Extraction}

The DNA of the fresh samples was extracted using the commercial kit called "DNA-Sorb-A" from sacace biotechnologies ${ }^{\circledR}$ according to the manufacturer's protocol. The archived samples fixed and embedded in paraffin blocks were cut and DNA was extracted using the commercial FFPE DNA Purification kit from (NORGEN BIOTECH CORPORATION, Canada). Xylene was used for dewaxing the samples before the actual extraction according to the manufacturer's protocol. The DNA extracted from the two types of sample was stored at $-20^{\circ} \mathrm{C}$ for PCR amplifications.

\subsection{HR-HPV Detection}

The detection of HR-HPV was carried out with the HPV Genotypes 14 Real-TMQuant kit (SACACE Biotechnologies ${ }^{\circ}$, Italy) by real-time multiplex PCR test for the detection of 14 high-risk genotypes (HPV-16, 18, 31, 33, 35, 39, $45,51,52,56,58,59,66$ and 68$)$ as describe in the previous studies from our laboratory [9] [24] [25] [26].

\subsection{GSTM1 Polymorphism Detection}

The conventional multiplex PCR method described by Chen et al. was used for the GSTM1 genotyping [27]. Each PCR well contained $10 \mu \mathrm{L}$ of Taq Gold 360 Master Mix Ampli, $1 \mu \mathrm{L}$ of each primer, $7 \mu \mathrm{L}$ of sterile water and $2 \mu \mathrm{L}$ of DNA. The PCR amplification program was as follow: a denaturation step at $94^{\circ} \mathrm{C}$ for 5 minutes followed by 35 cycles at $94^{\circ} \mathrm{C}$ for 1 minute, $57^{\circ} \mathrm{C}$ for 1 minute and $72^{\circ} \mathrm{C}$ for 1 minute, ending with an extension at $72^{\circ} \mathrm{C}$ for 7 minutes. PCR products were separated by electrophoresis through a $3 \%$ agarose gel containing ethidium bromide (Figure 1). The GSTM1 and $\beta$-globin amplicons size were expected at $215 \mathrm{bp}$ and 268 , respectively. The absence of GSTM1 band in a positive $\beta$-globin sample was considered as null genotype and PCR was invalid in the absence of the $\beta$-globin band.

\subsection{Ethical Considerations}

The women enrolled in the present study gave their free and informed consent according to the declaration of Helsinki. The confidentiality of patients' information was maintained for the retrospectively-collected data from the medical records. Ethics Committee for Health Research (CERS) of Burkina Faso approved the research protocol of the study with deliberation $\mathrm{N}^{\circ} 2018-01-012$ of January 10, 2018. 


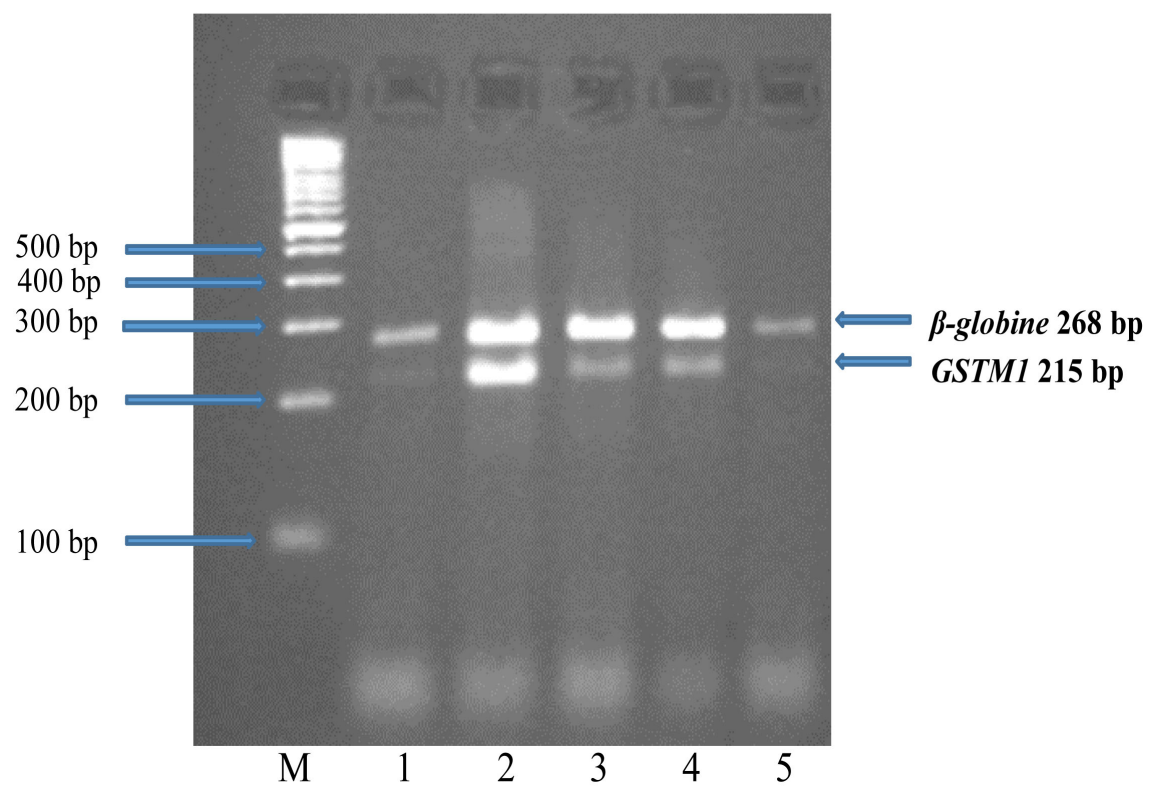

Figure 1. PCR-multiplex electrophoresis gel. Legend: $M=$ Molecular weight marker (100 bp); Samples 1 and 5 = genotypes null of GSTM1; Samples 2; 3 and $4=$ Genotypes of GSTM1 present.

\subsection{Statistical Analysis}

Data were analyzed using Excel 2016, SPSS statistics 25.0.0.0 and Epi Info 7.2.2.6 software. The confidence interval was set at $95 \%$. Fisher test and the odds ratio were used for comparison. The difference was statistically significant for $\mathrm{p}<$ 0.05 .

\section{Results}

\subsection{Socio-Demographic Characteristics of the Women in the Study}

The 232 women were found to have cervical lesions and had age ranging from 18 to 82 years with a mean of $44.24 \pm 14.10$ years while that of the 100 controls ranged from 18 to 57 years of age with a mean of $34.90 \pm 9.2$ years (Table 1). Women in the age group 35 - 44 were the most represented (31\%). and those in the age group $>35$ years old had a 3.33-fold higher risk for high grade squamous intraepithelial lesion (HSIL) or cancer $(95 \% \mathrm{CI}=2.04-5.42$; $\mathrm{p}<0.0001)$. According to the childbirth number as risk factor due by cervix weakening caused, compared to women without child or nulliparous, woman with one birth (primiparous), two (pauciparous), three to five (multiparous) and more than 5 (large multiparous) were high risk factor to develop cervical cancer disease in our study. The relative risks were strongly significant 5.04 (95\% CI $=1.39$ $18.24 ; \mathrm{p}=0.0159)$ in primiparous, $3.61(95 \% \mathrm{CI}=1.21-10.72 ; \mathrm{p}=0.0186)$ pauciparous, $8.03(95 \% \mathrm{CI}=2.67-24.08 ; \mathrm{p}<0.0001)$ multiparous and $24.26(95 \%$ $\mathrm{CI}=7.27-80.97 ; \mathrm{p}<0.0001)$ large multiparous respectively. Contraceptive use did not show significant correlation with cervical cancer in our study. 
Table 1. Baseline characteristics of the study groups.

\begin{tabular}{|c|c|c|c|c|c|c|}
\hline Variables & Controls & Cases & OR & $95 \% \mathrm{CI}$ & p-value & Total \\
\hline Women & 100 & 232 & & & & 332 \\
\hline Middle age & $34.90 \pm 9.2$ & $44.24 \pm 14.10$ & & & & $41.42 \pm 13.51$ \\
\hline \multicolumn{7}{|l|}{ Age Group iyrs } \\
\hline$\leq 35$ & 58 & 68 & Reference & & & 126 \\
\hline$>35$ & 42 & 164 & 3.33 & $2.04-5.42$ & $<0.0001$ & 206 \\
\hline \multicolumn{7}{|l|}{ Parity } \\
\hline Unknown & 1 & 88 & & & & 89 \\
\hline Nulliparous & 21 & 5 & Reference & & & 26 \\
\hline Primiparous & 10 & 12 & 5.04 & $1.39-18.24$ & 0.0159 & 22 \\
\hline Paupiparous & 36 & 31 & 3.61 & $1.21-10.72$ & 0.0186 & 67 \\
\hline Multiparous & 23 & 44 & 8.03 & $2.67-24.08$ & $<0.0001$ & 67 \\
\hline Great multiparous & 9 & 52 & 24.26 & $7.27-80.97$ & $<0.001$ & 61 \\
\hline \multicolumn{7}{|l|}{ Contraceptive } \\
\hline Unknown & 0 & 89 & & & & 89 \\
\hline No & 61 & 94 & Reference & & & 155 \\
\hline Yes & 39 & 49 & 0.81 & $0.48-1.38$ & 0.498 & 88 \\
\hline \multicolumn{7}{|l|}{ HR-HPV type } \\
\hline HPV16 & 1 & 13 & - & & & 14 \\
\hline HPV18 & 2 & 37 & - & & & 39 \\
\hline HPV31 & 2 & 22 & - & & & 24 \\
\hline HPV33 & 0 & 29 & - & & & 29 \\
\hline HPV35 & 1 & 12 & - & & & 13 \\
\hline HPV39 & 12 & 7 & - & & & 19 \\
\hline HPV45 & 7 & 19 & - & & & 26 \\
\hline HPV51 & 4 & 3 & - & & & 7 \\
\hline HPV52 & 9 & 12 & - & & & 21 \\
\hline HPV56 & 4 & 4 & - & & & 8 \\
\hline HPV58 & 2 & 4 & - & & & 6 \\
\hline HPV59 & 7 & 5 & - & & & 12 \\
\hline HPV66 & 0 & 5 & - & & & 5 \\
\hline HPV68 & 4 & 10 & - & & & 14 \\
\hline
\end{tabular}

Nulliparous: woman without a child; Primiparous: woman with one child; Paupiparous: woman with two or three children; Multiparous: woman with four or five children; Great multiparous: woman with more than 5 children.

\subsection{Distribution of GSTM1 Genotypes among Cases, Controls, and the Acquisition Risk of HSIL and Cervical Cancer}

Table 2 shows the distribution of GSTM1 polymorphisms among cases and controls. Women with GSTM1-null presented a risk to high-grade lesions and cervical cancer with relative risks of $10.77(95 \% \mathrm{CI}=5.59-20.72$; $\mathrm{p}<0.0001)$ and $13.20(95 \% \mathrm{CI}=6.79-25.63 ; \mathrm{p}<0.0001)$ respectively. Table 3 presents the 
Table 2. Distribution of GSTM genotype among cases, controls, and the acquisition risk of HSIL and cervical cancer.

\begin{tabular}{ccccccc}
\hline & & \multicolumn{7}{c}{ GSTM } & & & \\
\cline { 2 - 7 } & Variables & Null & Active & OR & 95\% CI & p-value \\
\hline Controls $(\mathrm{n}=100)$ & 25 & 75 & Ref & & \\
Cases $(\mathrm{n}=\mathbf{2 0 9})$ & 167 & 42 & 11.92 & $6.77-20.99$ & $<0.0001$ \\
Study & HSIL $(\mathrm{n}=101)$ & 79 & 22 & 10.77 & $5.59-20.72$ & $<0.0001$ \\
population & CIN2 $(\mathrm{n}=75)$ & 60 & 15 & 12.00 & $5.81-24.76$ & $<0.0001$ \\
& CIN3 $(\mathrm{n}=26)$ & 19 & 7 & 8.14 & $3.06-21.64$ & $<0.0001$ \\
& Cancer $(\mathrm{n}=108)$ & 88 & 20 & 13.20 & $6.79-25.63$ & $<0.0001$ \\
& Adenocarcinoma $(\mathrm{n}=9)$ & 7 & 2 & 10.50 & $2.04-53.88$ & 0.0025 \\
& Squamous cell carcinoma $(\mathrm{n}=99)$ & 81 & 18 & 13.50 & $6.82-26.71$ & $<0.0001$ \\
& Total $(\mathrm{n}=309)$ & 192 & 117 & & & \\
\hline
\end{tabular}

HSIL: high-grade squamous intraepithelial lesion. Ref: Reference. OR: Odds Ratio. IC: Confidence interval. p-value $<0.05$.

Table 3. GSTM null polymorphisms in the precancerous, cervical cancer lesions and control groups in Mali and Burkina.

\begin{tabular}{ccccccc}
\hline & & \multicolumn{5}{c}{ GSTM } \\
\cline { 2 - 7 } & Variables & Null & Active & OR & $95 \%$ CI & p-value \\
\hline \multirow{2}{*}{ Controls $(\mathrm{n}=100)$} & 25 & 75 & & Ref & \\
Furkina & HSIL $(\mathrm{n}=12)$ & 9 & 3 & 9 & $2.25-35.87$ & 0.00099 \\
& Cancer $(\mathrm{n}=\mathbf{6 0})$ & 50 & 10 & 15 & $6.63-33.92$ & $<0.0001$ \\
& Total $(\mathrm{n}=72)$ & 59 & 13 & & & \\
Mali & HSIL $(\mathrm{n}=\mathbf{8 9})$ & 70 & 19 & 11.05 & $5.60-21.80$ & $<0.0001$ \\
& Cancer $(\mathrm{n}=\mathbf{4 8})$ & 38 & 10 & 11.40 & $4.96-26.16$ & $<0.0001$ \\
& Total $(\mathrm{n}=137)$ & 108 & 29 & & & \\
\hline
\end{tabular}

HSIL: high-grade squamous intraepithelial lesion. Ref: Reference. OR: Odds Ratio. CI: Confidence interval. p-value $<0.05$.

relative risks observed in Burkina Faso and Mali. Women with GSTM1-null presented statistically significant results with 9 and 11.05-fold higher risk for developing high-grade lesions, 15 and 11.40-fold for cancer in Burkina Faso and Mali respectively. According to women with HR-HPV infection or no, GSTM1-null was significant results in both (Table 4). Women with GSTM1-null HR-HPV positive had 11.39-fold higher risk for high-grade squamous intraepithelial lesion (95\% CI $=3.87-33.50 ; \mathrm{p}<0.0001)$, and 16.11-fold higher risk for cervical cancer $(95 \% \mathrm{CI}=5.62-46.10 ; \mathrm{p}<0.0001)$. Women with $G S T M 1$-null HR-HPV negative had 13.92-fold higher risk for high-grade squamous intraepithelial lesion $(95 \% \mathrm{CI}=5.53-34.98 ; \mathrm{p}<0.0001)$, and 18.40-fold higher risk for cervical cancer $(95 \% \mathrm{CI}=6.28-53.89 ; \mathrm{p}<0.0001)$. 
Table 4. GSTM genotypes and their association with HPV status in controls and cervical cancer.

\begin{tabular}{ccccccc}
\hline & \multicolumn{7}{c}{ GSTM1 } \\
\cline { 2 - 7 } & Histology & Null & Active & OR & 95\% CI & p-value \\
\hline Control $(\mathrm{n}=65)$ & 19 & 46 & Ref & & \\
HPV- & HSIL $(\mathrm{n}=54)$ & 46 & 8 & 13.92 & $5.53-34.98$ & $<0.0001$ \\
& Cancer $(\mathrm{n}=43)$ & 38 & 5 & 18.40 & $6.28-53.89$ & $<0.0001$ \\
HPV+ & Total $(\mathrm{n}=162)$ & 103 & 59 & & & \\
Control $(\mathrm{n}=35)$ & 6 & 29 & Ref & & \\
HSIL $(\mathrm{n}=47)$ & 33 & 14 & 11.39 & $3.87-33.50$ & $<0.0001$ \\
& Cancer $(\mathrm{n}=65)$ & 50 & 15 & 16.11 & $5.62-46.10$ & $<0.0001$ \\
& Total $(\mathrm{n}=147)$ & 89 & 58 & & & \\
\hline
\end{tabular}

HSIL: high-grade squamous intraepithelial lesion. Ref: Reference. OR: Odds Ratio. CI: Confidence interval. p-value $<0.05$.

\section{Discussion}

The present case-control study compared GSTM1 deletion polymorphisms in HPV-infected women with normal cytology and those with precancerous lesions or cancer in order to determine the implication of GSTM1 polymorphisms in progression to cancer.

Glutathione S-Transferase M1-null was associated with the development of cancer in women HPV positive [28]. It was therefore obvious that the genetic polymorphisms of metabolic enzymes, by causing oxidative stress, would play a role in carcinogenesis modifying the cervical carcinogenic process induced by HPV infection.

In our study, the GSTM1-null genotype compared to the GSTM1-active genotype, we observed statistically significant frequencies with high relative risks for development of HSIL and cancer, respectively in Burkina (OR $=9$ and 15), Mali $(\mathrm{OR}=11.05$ and 11.40) and in general study people $(\mathrm{OR}=10.77$ and 13.20). Another author found a low relative risk than ours. In India, some authors had observed 2.62 and 4.01 relative risks for progression to cancer respectively [29] [30]. Women with GSTM1-null genotype compared to the controls in Serbia, had statistically significant frequencies and important risk $(\mathrm{OR}=2.26)$ [31] and in India $(\mathrm{OR}=2.39)$ [32]. These risks were also lower than ours $(\mathrm{OR}=$ 11.92). The high relative risks in our study could be due to environmental factors such as inhaling smoke from firewood used for cooking, food hygiene, high risk HPV-infection other genital infection in low- and middle-income countries and increased GSTM1-null risk factor, for examples early sexual debut pregnancy, high parity [33], polygamy [34] and the high prevalence of HIV infection [35]. In addition, insufficient awareness and poor knowledge of cervical cancer [36], false beliefs about cancer [37], low proportion of women attending cancer screening [38], the lack of financial resources and facilities for cervical cancer 
screening in rural area and poor social and hygienic conditions are important environmental cofactors risk for cervical cancer [39].

However, no significant results of GSTM1-null genotype have been encountered in India, Turkey and Italy for cancers [30] [40] [41] [42] and HSIL [29] [42] [43]. In Brazil, after a 60-month follow-up, Tacca et al. [44] determined $80.0 \%$ survival in women with GSTM1-active and $73.3 \%$ in women with GSTM1-null. Their results were also statistically no significant $(\mathrm{p}=0.368)$. The possible explanation could be the existence of geographic differences according to the population studied, of the association of the GSTM1-null factor with cancer of the cervix. These results should lead us to exploit other factors that can be associated with GSTM1-null factor to increase the risk for cervical cancer in our countries.

In women with HPV+ or HPV- we also observed significant results with increased risks 11 to 19 in the null genotype of GSTM1 compared to the active genotype for HSILs as for cancers. Therefore, GSTM1-null risk factor for cervical cancer was no dependent on HPV-infection. In Hungary after 7 years of follow up, Cseh et al. [45] found significant results for the same genotype GSTM1-null in women with persistent HR-HPV infection (OR = 1.78). In India, an increased risk higher than ours was observed precisely in women infected with HPV16 (OR = 31.39).

The socio-demographic characteristics and samples size of the studies cited differ from one study to another (smoking status, smoke from firewood, etc.). Several studies have used colposcopy and/or histology diagnostic test for cervical dysplasia. In our study, the VIA/VILI test was only used for controls. The difference of ethnic origin in the transmission of functional polymorphisms of genes metabolizing xenobiotics [46] could be a key factor in the differences in risks observed in Burkina Faso and Mali.

Blood samples were used considered by the different studies on the genotyping of GSTM1 polymorphisms. Our samples involved cells or tissues from the organ-infected or susceptible to be infected; allowing to study the GSTM1 polymorphisms on cells of the target organ of HPV. Since the virus infects cervical cells, DNA damage could be caused by the virus involving a high relative risk. This could also be an advantage for our study, used endocervical and tissue samples of women.

Our study was carried out on samples of treated tissue, coated with paraffin and archived; this could be a limitation. It would be judicious to carry out a study in which the patients will be followed up as well as a comparison between genotyping of GSTM1-null blood and tissues, being able to constitute a track for possible research on polymorphisms.

\section{Conclusion}

The results of the present study demonstrated an association between glutathione S-transferase polymorphisms and progression to high-grade precancer- 
ous lesions and cervical cancer among women in Burkina Faso and Mali. Deep knowledge about the specific role of host GST genes polymorphisms in the progression of HPV infection to cancer through a longitudinal study is required in low income countries such as Burkina Faso and Mali with high prevalence of cervical cancer. Altogether the understanding of these mechanisms is of interest to improve HPV prevention and management especially in West African countries in the context of emergence of non-HPV16/18 genotypes suggested by recent studies.

\section{Acknowledgements}

We would like to thank the "International Centre for Genetic Engineering and Biotechnology $(I C G E B)$ " for the funding of this research work through the project: "Implication of the host genetic factor in Human Papillomavirus Infection and its associated Cervical lesions and cancer in West African Women". Ref. No. CRP/BFA17-01. We also thank the "Agence Universitaire de la Francophonie" for the financial support and the CERBA/LABIOGENE.

\section{Conflicts of Interest}

The authors have not declared any conflict of interest.

\section{References}

[1] Bosch, F.X., Lorincz, A., Muñoz, N., Meijer, C. and Shah, K.V. (2002) The Causal Relation between Human Papillomavirus and Cervical Cancer. Journal of Clinical Pathology, 55, 244-265. https://doi.org/10.1136/jcp.55.4.244

[2] Walboomers, J.M., Jacobs, M.V., Manos, M.M., Bosch, F.X., Kummer, J.A., Shah, K.V., Snijders, P.J., Peto, J., Meijer, C.J. and Muñoz, N. (1999) Human Papillomavirus Is a Necessary Cause of Invasive Cervical Cancer Worldwide. The Journal of Pathology, 189, 12-19.

https://doi.org/10.1002/(SICI)1096-9896(199909)189:1<12::AID-PATH431>3.0.CO; $\underline{2-\mathrm{F}}$

[3] Bray, F., Ferlay, J., Soerjomataram, I., Siegel, R.L., Torre, L.A. and Jemal, A. (2018) Global Cancer Statistics 2018: GLOBOCAN Estimates of Incidence and Mortality Worldwide for 36 Cancers in 185 Countries. CA: A Cancer Journal for Clinicians, 68, 394-424. https://doi.org/10.3322/caac.21492

[4] Chuang, L.T., Temin, S., Camacho, R., Dueñas-Gonzalez, A., Feldman, S., Gultekin, M., Gupta, V., Horton, S., Jacob, G. and Kidd, E.A. (2016) Management and Care of Women with Invasive Cervical Cancer: American Society of Clinical Oncology Resource-Stratified Clinical Practice Guideline. Journal of global oncology, 2, 311-340. https://doi.org/10.1200/JGO.2016.003954

[5] Randall, T.C. and Ghebre, R. (2016) Challenges in Prevention and Care Delivery for Women with Cervical Cancer in Sub-Saharan Africa. Frontiers in oncology, 6, 160. https://doi.org/10.3389/fonc.2016.00160

[6] Bruni, L., Albero, G., Serrano, B., Mena, M., Gómez, D., Muñoz, J., Bosch, F. and de Sanjosé, S. (2019) ICO/IARC Information Centre on HPV and Cancer (HPV Information Centre). Human Papillomavirus and Related Diseases in Mali. Summary Report. https://www.hpvcentre.net 
[7] Bruni, L., Albero, G., Serrano, B., Mena, M., Gómez, D., Muñoz, J., Bosch, F. and de Sanjosé, S. (2018) ICO/IARC Information Centre on HPV and Cancer (HPV Information Centre). Human Papillomavirus and Related Diseases in Burkina Faso. Summary Report. https://www.hpvcentre.net

[8] Zohoncon, T., Bado, P., Ouermi, D., Traoré, E.M., Ouattara, S., Djigma, F., Traoré, I., Yonli, A.T., Obiri-Yeboah, D., Ouédraogo, C., et al. (2016) Molecular Characterization of High-Risk Human Papillomavirus Genotypes Involved in Invasive Cervical Cancer from Formalin-Fixed, Paraffin-Embedded Tissues in Ouagadougou, Burkina Faso. International Journal of Current Research, 8, 39314-39318.

[9] Ouédraogo, C., Zohoncon, T.M., Traoré, E.M., Ouattara, S., Bado, P., Ouedraogo, C.T., Djigma, F.W., Ouermi, D., Obiri-Yeboah, D. and Lompo, O. (2016) Distribution of High-Risk Human Papillomavirus Genotypes in Precancerous Cervical Lesions in Ouagadougou, Burkina Faso. Open Journal of Obstetrics and Gynecology, 6, 196. https://doi.org/10.4236/ojog.2016.64025

[10] Munoz, N. (2000) Human Papillomavirus and Cancer: The Epidemiological Evidence. Journal of Clinical Virology, 19, 1-5. https://doi.org/10.1016/S1386-6532(00)00125-6

[11] Sheweita, S.A. (2000) Drug-Metabolizing Enzymes Mechanisms and Functions. Current Drug Metabolism, 1, 107-132. https://doi.org/10.2174/1389200003339117

[12] Wilce, M.C. and Parker, M.W. (1994) Structure and Function of Glutathione S-Transferases. Biochimica et Biophysica Acta (BBA)-Protein Structure and Molecular Enzymology, 1205, 1-18. https://doi.org/10.1016/0167-4838(94)90086-8

[13] Armstrong, R.N. (1997) Structure, Catalytic Mechanism and Evolution of the Glutathione Transferases. Chemical Research in Toxicology, 10, 2-18. https://doi.org/10.1021/tx960072x

[14] Strange, R.C., Spiteri, M.A., Ramachandran, S. and Fryer, A.A. (2001) Glutathione-S-Transferase Family of Enzymes. Mutation Research/Fundamental and Molecular Mechanisms of Mutagenesis, 482, 21-26. https://doi.org/10.1016/S0027-5107(01)00206-8

[15] Board, P.G., Coggan, M., Chelvanayagam, G., Easteal, S., Jermiin, L.S., Schulte, G.K., Danley, D.E., Hoth, L.R., Griffor, M.C. and Kamath, A.V. (2000) Identification, Characterization and Crystal Structure of the Omega Class Glutathione Transferases. Journal of Biological Chemistry, 275, 24798-24806. https://doi.org/10.1074/jbc.M001706200

[16] Mannervik, B., Helena Danielson, U. and Ketterer, B. (1988) Glutathione Transferases-Structure and Catalytic Activit. Critical Reviews in Biochemistry, 23, 283-337. https://doi.org/10.3109/10409238809088226

[17] Kirk, G.D., Turner, P.C., Gong, Y., Lesi, O.A., Mendy, M., Goedert, J.J., Hall, A.J., Whittle, H., Hainaut, P. and Montesano, R. (2005) Hepatocellular Carcinoma and Polymorphisms in Carcinogen-Metabolizing and DNA Repair Enzymes in a Population with Aflatoxin Exposure and Hepatitis B Virus Endemicity. Cancer Epidemiology and Prevention Biomarkers, 14, 373-379.

https://doi.org/10.1158/1055-9965.EPI-04-0161

[18] Nomani, H., Mozafari, H., Ghobadloo, S.M., Rahimi, Z., Raygani, A.V., Rahimi, M.A., Haghi, A.F. and Keshavarz, A.A. (2011) The Association between GSTT1, M1 and P1 Polymorphisms with Coronary Artery Disease in Western Iran. Molecular and Cellular Biochemistry, 354, 181-187.

https://doi.org/10.1007/s11010-011-0817-2

[19] Sui, Y., Han, W., Yang, Z., Jiang, M. and Li, J. (2011) Association of Glutathione 
S-Transferase M1 and T1 Null Polymorphisms with the Development of Cervical Lesions: A Meta-Analysis. European Journal of Obstetrics \& Gynecology and Reproductive Biology, 159, 443-448. https://doi.org/10.1016/j.ejogrb.2011.09.012

[20] Lu, L., Wu, W., Tu, Y., Yang, Z., He, L. and Guo, M. (2014) Association of Glutathione S-Transferase M1/T1 Polymorphisms with Susceptibility to Vitiligo. Gene, 535, 12-16. https://doi.org/10.1016/j.gene.2013.11.024

[21] Soto-Quintana, O., Zúñiga-González, G., Ramírez-Patiño, R., Ramos-Silva, A., Figuera, L., Carrillo-Moreno, D., Gutiérrez-Hurtado, I., Puebla-Pérez, A., Sánchez-Llamas, B. and Gallegos-Arreola, M. (2015) Association of the GSTM1 Null Polymorphism with Breast Cancer in a Mexican Population. Genetics and Molecular Research, 14, 13066-13075. https://doi.org/10.4238/2015.October.26.2

[22] Khabaz, M., Nedjadi, T., Gari, M., Al-Maghrabi, J., Atta, H., Bakarman, M. and Gazzaz, Z. (2016) GSTM1 Gene Polymorphism and the Risk of Colorectal Cancer in a Saudi Arabian Population. Genetics and Molecular Research, 15.

https://doi.org/10.4238/gmr.15017551

[23] Zohoncon, T.M., Djigma, W.F., Ouattara, A.K., Traore, I.M.A., Ouedraogo, R.A., A., T.E.M., Bado, P., Ouedraogo, T.C., Diarra, B., Ilboudo, M., et al. (2020) Mapping of Fourteen High-Risk Human Papillomavirus Genotypes by Molecular Detection in Sexually Active Women in the West African Sub-Region. International Journal of Genetics and Molecular Biology, 12, 11-21.

[24] Zohoncon, T., Ouedraogo, T., Brun, L., Obiri-Yeboah, D., Djigma, W., Kabibou, S., Ouattara, S., Gomina, M., Yonli, A. and Bazie, V. (2016) Molecular Epidemiology of High-Risk Human Papillomavirus in High-Grade Cervical Intraepithelial Neoplasia and in Cervical Cancer in Parakou, Republic of Benin. Pakistan Journal of Biological Sciences, 19, 49-56. https://doi.org/10.3923/pjbs.2016.49.56

[25] Traore, I., Zohoncon, T., Ndo, O., Djigma, F., Obiri-Yeboah, D., Compaore, T., Guigma, S., Yonli, A., Traore, G. and Ouedraogo, P. (2016) Oncogenic Human Papillomavirus Infection and Genotype Characterization among Women in Orodara, Western Burkina Faso. Pakistan Journal of Biological Sciences, 19, 306-311. https://doi.org/10.3923/pjbs.2016.306.311

[26] Ouedraogo, R.A., Zohoncon, T.M., Guigma, S.P., Traore, I.M.A., Ouattara, A.K., Ouedraogo, M., Djigma, F.W., Obiri-Yeboah, D., Ouedraogo, C. and Simpore, J. (2018) Oncogenic Human Papillomavirus Infection and Genotypes Characterization among Sexually Active Women in Tenkodogo at Burkina Faso, West Africa. Papillomavirus Research, 6, 22-26. https://doi.org/10.1016/j.pvr.2018.09.001

[27] Chen, C.-L., Liu, Q., Pui, C.-H., Rivera, G.K., Sandlund, J.T., Ribeiro, R., Evans, W.E. and Relling, M.V. (1997) Higher Frequency of Glutathione S-Transferase Deletions in Black Children with Acute Lymphoblastic Leukemia. Blood, 89, 1701-1707. https://doi.org/10.1182/blood.V89.5.1701

[28] Lee, S.-A., Kim, J.W., Roh, J.W., Choi, J.Y., Lee, K.-M., Yoo, K.-Y., Song, Y.S. and Kang, D. (2004) Genetic Polymorphisms of GSTM1, p21, p53 and HPV Infection with Cervical Cancer in Korean Women. Gynecologic Oncology, 93, 14-18. https://doi.org/10.1016/j.ygyno.2003.11.045

[29] Sharma, A., Gupta, S., Sodhani, P., Singh, V., Sehgal, A., Sardana, S., Mehrotra, R. and Sharma, J.K. (2015) Glutathione s-Transferase m1 and t1 Polymorphisms, Cigarette Smoking and HPV Infection in Precancerous and Cancerous Lesions of the Uterine Cervix. Asian Pacific Journal of Cancer Prevention, 16, 6429-6438. https://doi.org/10.7314/APJCP.2015.16.15.6429

[30] Abbas, M., Srivastava, K., Imran, M. and Banerjee, M. (2013) Association of Gluta- 
thione S-Transferase (GSTM1, GSTT1 and GSTP1) Polymorphisms and Passive Smoking in Cervical Cancer Cases from North India. International Journal of Biomedical Research, 4, 655-662. https://doi.org/10.7439/ijbr.v4i12.396

[31] Stosic, I., Grujicic, D., Arsenijevic, S., Brkic, M. and Milosevic-Djordjevic, O. (2014) Glutathione S-Transferase T1 and M1 Polymorphisms and Risk of Uterine Cervical Lesions in Women from Central Serbia. Asian Pacific Journal of Cancer Prevention, 15, 3201-3205. https://doi.org/10.7314/APJCP.2014.15.7.3201

[32] Joseph, T., Chacko, P., Wesley, R., Jayaprakash, P., James, F.V. and Pillai, M.R. (2006) Germline Genetic Polymorphisms of CYP1A1, GSTM1 and GSTT1 Genes in Indian Cervical Cancer: Associations with Tumor Progression, Age and Human Papillomavirus Infection. Gynecologic Oncology, 101, 411-417. https://doi.org/10.1016/j.ygyno.2005.10.033

[33] Louie, K., De Sanjose, S., Diaz, M., Castellsague, X., Herrero, R., Meijer, C., Shah, K., Franceschi, S., Muñoz, N. and Bosch, F. (2009) Early Age at First Sexual Intercourse and Early Pregnancy Are Risk Factors for Cervical Cancer in Developing Countries. British Journal of Cancer, 100, 1191. https://doi.org/10.1038/sj.bjc.6604974

[34] Bayo, S., Bosch, F.X., de Sanjosé, S., Muñoz, N., Combita, A.L., Coursaget, P., Diaz, M., Dolo, A., van den Brule, A.J. and Meijer, C.J. (2002) Risk Factors of Invasive Cervical Cancer in Mali. International Journal of Epidemiology, 31, 202-209. https://doi.org/10.1093/ije/31.1.202

[35] Buga, G. (1998) Cervical Cancer Awareness and Risk Factors among Female University Students. East African Medical Journal, 75, 411-416.

[36] Anorlu, R., Orakwue, C., Oyeneyin, L. and Abudu, O. (2004) Late Presentation of Patients with Cervical Cancer to a Tertiary Hospital in Lagos: What Is Responsible? European Journal of Gynaecological Oncology, 25, 729-732.

[37] Anorlu, R., Ribiu, K., Abudu, O. and Ola, E. (2007) Cervical Cancer Screening Practices among General Practitioners in Lagos Nigeria. Journal of Obstetrics and $G y$ naecology, 27, 181-184. https://doi.org/10.1080/01443610601124398

[38] Gichangi, P., Estambale, B., Bwayo, J., Rogo, K., Ojwang, S., Opiyo, A. and Temmerman, M. (2003) Knowledge and Practice about Cervical Cancer and Pap Smear Testing among Patients at Kenyatta National Hospital, Nairobi, Kenya. International Journal of Gynecologic Cancer, 13, 827-833. https://doi.org/10.1136/ijgc-00009577-200311000-00014

[39] Palacio-Mejía, L.S., Rangel-Gómez, G., Hernández-Avila, M. and Lazcano-Ponce, E. (2003) Cervical Cancer, a Disease of Poverty: Mortality Differences between Urban and Rural Areas in Mexico. Salud pública de méxico, 45, 315-325. https://doi.org/10.1590/S0036-36342003000900005

[40] Satinder, K., Sobti, R. and Pushpinder, K. (2017) Impact of Single Nucleotide Polymorphism in Chemical Metabolizing Genes and Exposure to Wood Smoke on Risk of Cervical Cancer in North-Indian Women. Experimental Oncology, 39, 69-74. https://doi.org/10.31768/2312-8852.2017.39(1):69-74

[41] Kiran, B., Karkucak, M., Ozan, H., Yakut, T., Ozerkan, K., Sag, S. and Ture, M. (2010) GST (GSTM1, GSTT1 and GSTP1) Polymorphisms in the Genetic Susceptibility of Turkish Patients to Cervical Cancer. Journal of Gynecologic Oncology, 21, 169-173. https://doi.org/10.3802/jgo.2010.21.3.169

[42] Palma, S., Novelli, F., Padua, L., Venuti, A., Prignano, G., Mariani, L., Cozzi, R., Tirindelli, D. and Testa, A. (2010) Interaction between Glutathione-S-Transferase Polymorphisms, Smoking Habit and HPV Infection in Cervical Cancer Risk. Journal 
of Cancer Research and Clinical Oncology, 136, 1101-1109.

https://doi.org/10.1007/s00432-009-0757-3

[43] Agodi, A., Barchitta, M., Cipresso, R., Marzagalli, R., La Rosa, N., Caruso, M., Castiglione, M.G. and Travali, S. (2010) Distribution of p53, GST and MTHFR Polymorphisms and Risk of Cervical Intraepithelial Lesions in Sicily. International Journal of Gynecologic Cancer, 20, 141-146. https://doi.org/10.1111/IGC.0b013e3181c20842

[44] Tacca, A.L.c.M., Lopes, A.K., Vilanova-Costa, C.A.S.T., Silva, A.M.T.C., Costa, S.H.N., Nogueira, N.A., Ramos, J.E.P., Ribeiro, A.A. and Saddi, V.A. (2018) Null Polymorphisms in GSTT1 and GSTM1 Genes and Their Associations with Smoking and Cervical Cancer. Genetics and Molecular Research, 17, gmr16039918. https://doi.org/10.4238/gmr18067

[45] Cseh, J., Pazsit, E., Orsos, Z., Marek, E., Huszar, A., Balogh, S., Ember, I. and Kiss, I. (2011) Effect of Glutathione-S-Transferase M1 and T1 Allelic Polymorphisms on HPV-Induced Cervical Precancer Formation. Anticancer Research, 31, 3051-3055.

[46] Lang, M. and Pelkonen, O. (1999) Metabolism of Xenobiotics and Chemical Carcinogenesis. IARC Scientific Publications, 13-22. 